\title{
CRESCIMENTO E DESENVOLVIMENTO DA ALFACE (Lactuca sativa L.) CONDUZIDA EM ESTUFA PLÁSTICA COM FERTIRRIGAÇÃO EM SUBSTRATOS
}

\author{
GROWTH AND DEVELOPMENT OF LETTUCE (Lactuca sativa L.) IN A PLASTIC \\ GREENHOUSE WITH FERTIRRIGATION IN SUBSTRATES
}

\author{
Luis Aquiles Martins Medeiros ${ }^{1}$ Paulo Augusto Manfron ${ }^{2}$ Sandro Luis Petter Medeiros ${ }^{3}$ \\ Reinaldo A. G. Bonnecarrère ${ }^{4}$
}

RESUMO

\begin{abstract}
Foram conduzidos dois experimentos, um cultivo no outono e outro no inverno de 1998, em estufa plástica localizada no Departamento de Fitotecnia da Universidade Federal de Santa Maria, com o objetivo de estudar a influência da fertirrigação em substratos no crescimento e desenvolvimento da alface, cultivar Brisa. Os tratamentos, com e sem fertirrigação, foram constituídos pelos substratos húmus de minhoca mais casca de arroz natural $(H+C N)$, húmus de minhoca mais casca de arroz carbonizada $(H+C C)$ e solo como testemunha, constituindo um bifatorial 3x2. A fertirrigação foi realizada em função da condutividade elétrica (CE) da solução drenada dos substratos. O delineamento experimental utilizado foi de blocos casualizados com quatro repetições. Semanalmente, foram determinados o número de folhas por planta, a massa fresca e seca da parte aérea das plantas e o índice de área foliar. Avaliou-se, ainda, a capacidade de retenção de água (CRa) dos substratos isolados e das misturas, antes e após os cultivos. A CRa dos substratos aumentou ao longo dos cultivos enquanto a do solo permaneceu constante. Os substratos irrigados com solução nutritiva proporcionaram maior número de folhas, maior produção de massa fresca e seca da parte aérea e maior índice de área foliar do que quando irrigados apenas com água, sendo que os substratos $\mathrm{H}+\mathrm{CN}$ e $\mathrm{H}+\mathrm{CC}$ foram significativamente mais produtivos do que o substrato testemunha em ambos os cultivos.
\end{abstract}

Palavras-chave: húmus de minhoca, casca de arroz, casca de arroz carbonizada.

\section{SUMMARY}

In order to study the effects of fertirrigation in growing substrates on the development of lettuce cultivar Brisa, two essays were conducted, one during the fall of 1998 and the other during the winter, in a plastic greenhouse in the Federal University of Santa Maria. The treatments with and without fertirrigation were constituted by earthworm humus plus rice hulls $(H+C N)$, earthworm humus plus carbonized rice hulls $(H+C C)$ and pure soil as check. The fertirrigation timing was established by monitoring the electric conductivity of the substrates drained solution. The experimental design was a randomized block with four replications. Once a week, the number of leaves per plant, fresh and dry weight of above ground plant parts and leaf area index were determined. The water retention capacity $(\mathrm{CRa})$ of the isolated substrates and mixtures both before and after the establishment of the plants was also determined. The substrates CRa values increased along the growing season whereas soil CRa was constant. The substrates irrigated with nutritive solution resulted in plants with greater leaf numbers, higher dry and fresh above ground weight and higher leaf area index when compared with plants irrigated with water only. The $H+C N$ and $H+C C$ substrates were significantly more productive that the check substrates in both growing seasons.

Key words: earthworm humus, rice hulls, carbonized rice hulls

\section{INTRODUÇÃO}

O cultivo comercial de hortaliças em estufas plásticas é uma atividade consolidada e crescente, principalmente nas proximidades das grandes concentrações urbanas, onde a capacidade de produ-

\footnotetext{
${ }^{1}$ Engenheiro Agrônomo, MSc., Professor da Escola Agrotécnica Federal de Rio do Sul, SC. Estrada do Redentor 5665. CP 441. 89160 000. E-mail: aquiles@ fatec.ufsm.br. Autor para correspondência.

${ }^{2}$ Engenheiro Agrônomo, Doutor, Professor Titular do Departamento de Fitotecnia, Centro de Ciências Rurais (CCR), Universidade Federal de Santa Maria (UFSM).

${ }^{3}$ Engenheiro Agrônomo, Doutor, Professor Adjunto do Departamento de Fitotecnia, CCR, UFSM.

${ }^{4}$ Acadêmico do Curso de Agronomia, bolsista FAPERGS - CCR, UFSM.
} 
ção intensiva em pequenas áreas atende a grande demanda que esses locais apresentam, tanto em quantidade como em qualidade de produtos hortifrutigranjeiros.

Por outro lado, a utilização intensiva dessas áreas implica ocorrência de doenças da parte aérea e sistema radicular das plantas e na salinização do solo. Para a maioria das doenças, o controle através do uso de produtos químicos para a esterilização do solo, tratamento de sementes e programas curativos/preventivos pode ser eficiente. No entanto, é oneroso e concorre negativamente para a imagem dos produtos "livres de agrotóxicos". A prática da solarização do solo também pode ser empregada com sucesso para o controle de patógenos, mas é dependente dos períodos do ano nos quais a insolação seja máxima (STRECK,1994). Quanto à salinização do solo, pode ser reduzida com irrigações abundantes, mas depende da permeabilidade do solo e pode contaminar o lençol freático.

As alternativas para resolver ou minimizar o efeito desses problemas, em cultivos protegidos por estufas plásticas, passam pelos sistemas de cultivo sem solo, onde a fertirrigação em substratos ganha destaque.

A utilização de substratos em substituição ao solo nos cultivos protegidos, segundo COLJAP INDÚSTRIA AGROQUÍMICA S.A., [s.d.], é uma prática muito utilizada em países de horticultura desenvolvida, justificando-se quando o solo apresenta fatores de ordem física, química e/ou biológica, limitantes ao desenvolvimento de plantas.

Para ANDRIOLO (1996), diversos materiais de origem orgânica e mineral podem ser empregados como substratos, sendo a disponibilidade e o custo, fatores determinantes na escolha. Porém, nem sempre um único material reúne todas as características desejáveis, devendo-se, às vezes, recorrer à mistura deles, buscando a complementação das características faltantes. Entretanto, BLISKA JÚNIOR \& HONÓRIO (1996) alertam que testes de materiais novos em diferentes proporções podem apresentar resultados discrepantes conforme a espécie utilizada.

A casca de arroz e o húmus de minhoca são materiais disponíveis e de baixo custo que em mistura podem caracterizar um bom substrato para a fertirrigação. O principal impedimento ao uso da casca de arroz, como substrato único, é a deficiência de conservação de umidade homogênea (COLJAP INDÚSTRIA AGROQUÍMICA S.A., [s.d.]) e a característica mais importante do húmus de minhoca, como substrato, é a capacidade de retenção de umidade (ANDRIOLO E POERSCHKE, 1997). O estudo desses materiais alternativos na composição de substratos para a fertirrigação da alface em estufa plástica traduz o objetivo deste trabalho.

\section{MATERIAL E MÉTODOS}

Os experimentos foram realizados no Departamento de Fitotecnia da Universidade Federal de Santa Maria, em uma estufa plástica modelo arcopampeana de $250 \mathrm{~m}^{2}$ (25m x 10m) com cobertura de policloreto de vinil (PVC) e constaram de duas épocas de cultivo, outono (06/04 a 14/06) e inverno (27/05 a 23/08) de 1998. O experimento estava disposto em um esquema fatorial $3 \times 2$ no delineamento de blocos ao acaso com 4 repetições. Os tratamentos foram formados pelo substrato solo como testemunha e por duas misturas, com e sem fertirrigação: húmus de minhoca $(70 \%)$ mais casca de arroz natural $(30 \%)$ e húmus de minhoca $(40 \%)$ mais casca de arroz carbonizada $(60 \%)$, proporções que determinam nas misturas capacidade de retenção de água (CRa) próxima de $50 \%$, considerada satisfatória por COLJAP INDÚSTRIA AGROQUÍMICA S.A. [s.d.]. O substrato solo foi corrigido e fertilizado segundo as recomendações da ROLAS para a cultura da alface. A casca de arroz carbonizada foi utilizada imediatamente após ter sido realizado o processo de carbonização. O leito de cultivo constituiu-se de telhas de cimento amianto do tipo "calhetão", assentadas ao nível do solo e divididas pela metade para formar as unidades experimentais $(3,25 \mathrm{~m} \mathrm{x}$ $1,00 \mathrm{~m})$. A irrigação e a fertirrigação foram realizadas através de dois sistemas independentes, sendo cada um formado por um reservatório, uma motobomba e tubogotejadores. No cultivo do outono, foram utilizados apenas dois tubogotejadores para três linhas de plantas, e no cultivo do inverno, um tubogotejador para cada linha de planta. Utilizou-se a cultivar de alface Brisa no espaçamento de $0,25 \mathrm{~m}$ entre plantas e $0,30 \mathrm{~m}$ entre as 3 filas de plantas, totalizando 32 plantas por parcela. A solução nutritiva utilizada foi proposta por CASTELANE E ARAÚJO (1995).

Semanalmente, foram avaliados, nas plantas da fila central, o número de folhas por planta, a massa fresca e seca da parte aérea e o índice de área foliar pelo "método da pesagem de discos" de Blackman e Wilson (1951), citados por LUCHESI (1987). Nos substratos, através da metodologia descrita por ANDRIOLO E POERSCHKE (1997), avaliou-se a capacidade de retenção de água dos componentes e das misturas, antes e após os cultivos e, semanalmente, avaliou-se a condutividade elétrica da solução drenada, que serviu de parâmetro para a realização das fertirrigações. 


\section{RESULTADOS E DISCUSSÃO}

A análise da variância mostrou efeito significativo somente para a fonte de variação irrigação (com ou sem fertirrigação) em todas as variáveis analisadas, sendo utilizado o teste Duncan para comparar as médias (Tabela 1). As irrigações não foram comparadas dentro de cada substrato, pois a interação entre a irrigação e os substratos não mostrou efeito significativo em todas as variáveis analisadas. A capacidade de retenção de água (CRa) dos substratos húmus mais casca de arroz natural $(\mathrm{H}+\mathrm{CN})$ e húmus mais casca de arroz carbonizada $(\mathrm{H}+\mathrm{CC})$ aumentou gradativamente ao longo dos cultivos, enquanto que a do solo permaneceu constante (Figura 1). Esse aumento foi determinado, provavelmente, pela diminuição do tamanho dos poros resultante da "acomodação" das partículas de cada componente, a qual foi visualmente constatada pela diminuição da espessura do leito de cultivo.

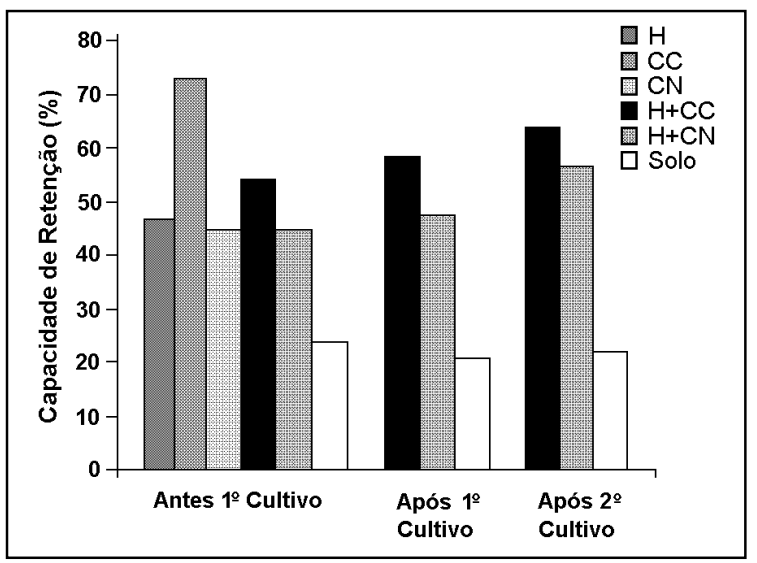

Figura 1 - Evolução da capacidade de retenção de água dos componentes: húmus de minhoca $(\mathrm{H})$, casca de arroz natural $(\mathrm{CN})$ e casca de arroz carbonizada (CC), e dos substratos: húmus mais casca de arroz natural $(\mathrm{H}+\mathrm{CN})$, húmus mais casca de arroz carbonizada $(\mathrm{H}+\mathrm{CC})$ e solo (testemunha), em diferentes épocas. Santa Maria, RS, 1998.
Tabela 1 - Médias do número de folhas por planta, da produção de massa fresca e seca (g/planta) e do índice de área foliar da cultivar de alface Brisa, conduzida em estufa plástica com e sem fertirrigação, em diferentes dias após o transplante. Santa Maria, RS, 1998.

\begin{tabular}{cccc}
\hline \multicolumn{3}{c}{ Outono } \\
\hline DAT & $\begin{array}{c}\text { Número de folhas } \\
\text { por planta }\end{array}$ & $\begin{array}{c}\text { Massa fresca da } \\
\text { parte aérea da planta }\end{array}$ & $\begin{array}{c}\text { Massa seca da parte } \\
\text { aérea da planta }\end{array}$ \\
\hline
\end{tabular}

Com fert. Sem fert. Com fert. Sem fert. Com fert. Sem fert. Com fert. Sem fert.

\begin{tabular}{|c|c|c|c|c|c|c|c|c|}
\hline 11 & - & - & $3,0 \mathrm{a}$ & $2,2 \mathrm{a}$ & $0,25 \mathrm{a}$ & $0,21 \mathrm{a}$ & $0,29 \mathrm{a}$ & $0,15 \mathrm{a}$ \\
\hline 14 & $6,4 a^{*}$ & $6,0 \mathrm{a}$ & $4,6 a$ & $3,9 \mathrm{a}$ & $0,21 \mathrm{a}$ & $0,19 \mathrm{a}$ & $0,45 \mathrm{a}$ & $0,21 \mathrm{a}$ \\
\hline 19 & $8,0 \mathrm{a}$ & $7,2 \mathrm{a}$ & $9,9 \mathrm{a}$ & $7,6 a$ & $0,57 \mathrm{a}$ & $0,46 \mathrm{a}$ & $0,55 \mathrm{a}$ & $0,41 \mathrm{a}$ \\
\hline 21 & $8,6 a$ & 7,6a & $14,1 \mathrm{a}$ & $10,2 \mathrm{a}$ & $0,80 \mathrm{a}$ & $0,56 \mathrm{a}$ & $1,91 \mathrm{a}$ & $1,24 b$ \\
\hline 25 & $10,4 \mathrm{a}$ & $10,0 \mathrm{a}$ & $25,8 \mathrm{a}$ & $21,4 a$ & $1,25 \mathrm{a}$ & $1,08 \mathrm{a}$ & $1,49 a$ & $1,63 \mathrm{a}$ \\
\hline 28 & $11,1 \mathrm{a}$ & $11,0 \mathrm{a}$ & $42,5 a$ & $37,6 a$ & $2,30 \mathrm{a}$ & $1,81 \mathrm{a}$ & $2,07 \mathrm{a}$ & $1,70 \mathrm{a}$ \\
\hline 33 & $14,4 \mathrm{a}$ & $13,5 \mathrm{a}$ & $65,8 \mathrm{a}$ & $43,4 a$ & $2,65 a$ & $2,21 \mathrm{a}$ & $2,08 \mathrm{a}$ & $1,57 \mathrm{a}$ \\
\hline 39 & $19,6 a$ & $17,0 \mathrm{a}$ & $189,8 \mathrm{a}$ & $86,3 b$ & $8,27 \mathrm{a}$ & $5,64 \mathrm{~b}$ & $8,08 \mathrm{a}$ & $4,70 \mathrm{~b}$ \\
\hline 43 & $22,5 a$ & $17,0 \mathrm{~b}$ & $297,1 \mathrm{a}$ & $121,3 b$ & $10,54 \mathrm{a}$ & $5,39 \mathrm{~b}$ & $11,67 \mathrm{a}$ & $5,26 \mathrm{~b}$ \\
\hline \multicolumn{9}{|c|}{ Inverno } \\
\hline 10 & $5,1 \mathrm{a}$ & $4,3 b$ & $2,3 a$ & $1,7 \mathrm{~b}$ & $0,14 \mathrm{a}$ & $0,12 \mathrm{a}$ & $0,16 \mathrm{a}$ & $0,12 b$ \\
\hline 17 & $6,8 \mathrm{a}$ & $5,3 b$ & $6,2 a$ & $2,2 b$ & $0,29 a$ & $0,15 b$ & $0,32 \mathrm{a}$ & $0,16 b$ \\
\hline 20 & $8,4 a$ & $6,2 b$ & $9,8 \mathrm{a}$ & $3,5 b$ & $0,45 \mathrm{a}$ & $0,21 b$ & $0,67 \mathrm{a}$ & $0,31 b$ \\
\hline 24 & $9,4 \mathrm{a}$ & $7,0 \mathrm{~b}$ & $16,4 a$ & $3,9 b$ & $0,73 a$ & $0,45 \mathrm{a}$ & $1,08 \mathrm{a}$ & $0,63 \mathrm{a}$ \\
\hline 27 & $9,2 \mathrm{a}$ & $7,2 \mathrm{~b}$ & $21,1 \mathrm{a}$ & $5,7 \mathrm{~b}$ & $1,01 \mathrm{a}$ & $0,29 b$ & $1,26 \mathrm{a}$ & $0,40 \mathrm{~b}$ \\
\hline 30 & $12,3 \mathrm{a}$ & $7,6 \mathrm{~b}$ & $38,5 \mathrm{a}$ & $8,1 \mathrm{~b}$ & $1,88 \mathrm{a}$ & $0,46 b$ & $2,48 \mathrm{a}$ & $0,65 b$ \\
\hline 37 & $15,0 \mathrm{a}$ & $10,6 \mathrm{~b}$ & $76,3 a$ & $18,0 \mathrm{~b}$ & $3,96 \mathrm{a}$ & $1,02 \mathrm{~b}$ & $4,33 \mathrm{a}$ & $1,02 b$ \\
\hline 44 & $17,7 \mathrm{a}$ & $12,8 b$ & $209,8 \mathrm{a}$ & $42,3 b$ & $7,64 \mathrm{a}$ & $2,04 \mathrm{~b}$ & $8,96 \mathrm{a}$ & $2,26 b$ \\
\hline 47 & $21,0 \mathrm{a}$ & $14,3 \mathrm{~b}$ & $223,1 \mathrm{a}$ & $52,5 b$ & $9,23 \mathrm{a}$ & $2,66 b$ & $10,44 \mathrm{a}$ & $3,06 \mathrm{~b}$ \\
\hline 51 & $20,6 a$ & $14,2 b$ & $250,2 \mathrm{a}$ & $85,9 b$ & $9,58 \mathrm{a}$ & $3,64 b$ & $10,89 a$ & $3,94 b$ \\
\hline
\end{tabular}

*= Tratamentos com médias seguidas por letras distintas na linha, para cada uma das variáveis, diferem entre si pelo teste de Duncan em nível de $5 \%$ de probabilidade de erro.
Nas duas épocas de cultivo, o substrato $\mathrm{H}+\mathrm{CC}$ apresentou o valor mais elevado de CRa, fato que pode ser atribuído à sua composição com $60 \%$ de casca de arroz carbonizada, que apresenta elevada CRa (Figura 1).

$\mathrm{O}$ substrato $\mathrm{H}+\mathrm{CN}$ teve sua CRa aumentada do primeiro (outono) para o segundo cultivo (inverno), também devido à compactação. Além disso, pode ter ocorrido um aumento intrínseco da CRa da casca de arroz natural com o tempo de permanência em condições de umidade, que de acordo com COLJAP INDUSTRIA AGROQUÍMICA S.A. [s.d.], seria decorrente de uma degradação física da casca.

No cultivo de outono (Figura 2a), observou-se que o número de folhas por planta (NF), alcançado pelos substratos $\mathrm{H}+\mathrm{CC}$ e solo fertirrigados, foi superior ao $\mathrm{NF}$ dos substratos irrigados com água a partir dos 27 dias após o transplante (DAT). O substrato $\mathrm{H}+\mathrm{CN}$, na mesma condição de irrigação, só eviden-

Ciência Rural, v. 31, n. 2, 2001. 


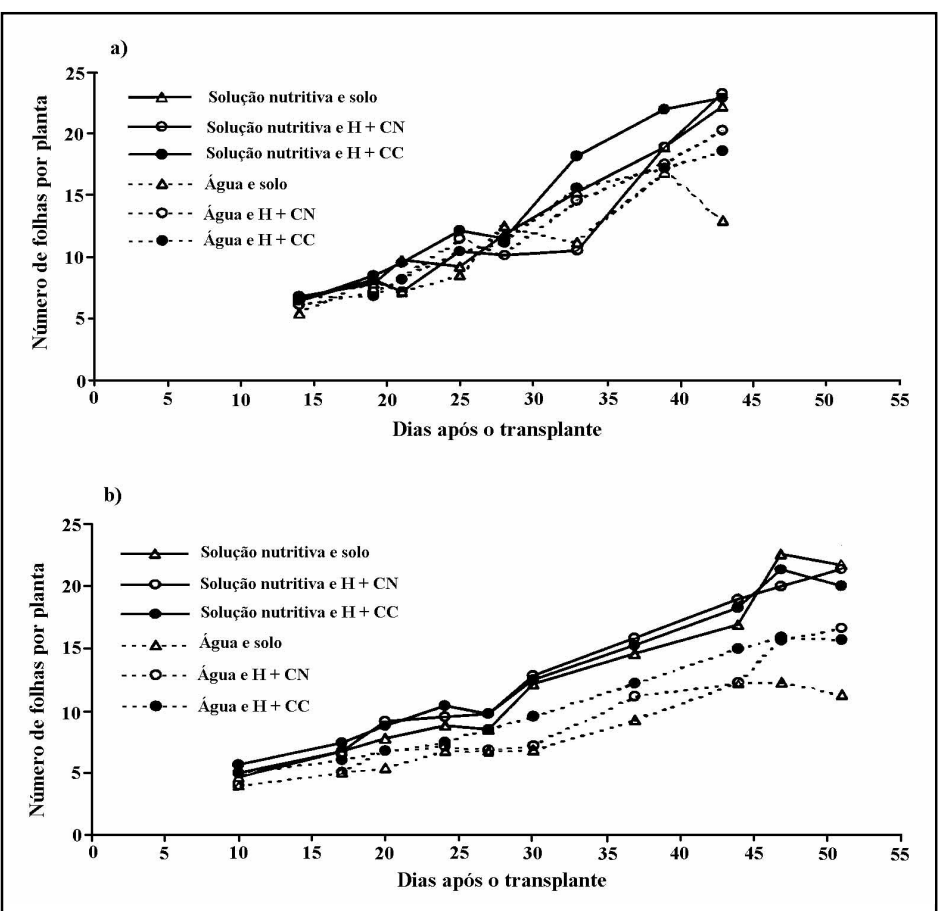

Figura 2 - Evolução do número de folhas por planta da cultivar de alface Brisa conduzida em ambiente protegido por estufa plástica em duas épocas de cultivo, a) outono e b) inverno, em diferentes substratos: húmus de minhoca mais casca de arroz natural $(\mathrm{H}+\mathrm{CN})$, húmus de minhoca mais casca de arroz carbonizada (H+CC) e solo (testemunha), com e sem solução nutritiva. Santa Maria, RS, 1998.

ciou sua superioridade ao final do ciclo, a partir dos 37DAT. No entanto, para o cultivo do inverno essa superioridade pode ser notada desde o início até o final do ciclo (Figura 2b), evidenciando maior velocidade de emissão de folhas nos substratos fertirrigados. Provavelmente, isso se deve à perda gradativa de nutrientes sofrida pelos substratos irrigados com água, aliada à retirada de nutrientes pelas plantas durante o cultivo anterior.

A maior produção de massa fresca (MFA), no outono, foi obtida pelos substratos fertirrigados (Figura 3a). Dentre os substratos, destacou-se o $\mathrm{H}+\mathrm{CC}$, no qual as plantas atingiram valores médios de massa fresca aceitáveis para a comercialização a partir dos 35DAT, valor este, citado por SEGOVIA (1991) como sendo maior ou igual a $150 \mathrm{~g}$ por cabeça. Esse fato pode ser explicado pela maior capacidade de retenção de água (Figura 1) e, conseqüentemente maior disponibilidade de nutrientes no substrato $\mathrm{H}+\mathrm{CC}$.
No cultivo de inverno, os substratos fertirrigados também proporcionaram maior ganho de massa fresca, o qual foi evidente desde as primeiras datas de coleta até o final do ciclo (Figura $3 b$ ). Analisando-se as figuras $3 a$ e $3 b$, observase que durante o inverno não houve destaque para a produção de massa fresca do substrato $\mathrm{H}+\mathrm{CC}$, em relação ao substrato $\mathrm{H}+\mathrm{CN}$, ambos fertirrigados, na mesma proporção ocorrida no cultivo do outono. Provavelmente, isso se deva ao equilíbrio do fornecimento hídrico, determinado pelo uso de um tubogotejador para cada linha de plantas e também ao aumento da $\mathrm{CRa}$ do substrato $\mathrm{H}+\mathrm{CN}$, devido ao envelhecimento da casca de arroz natural aliado à redução da macroporosidade, os quais determinaram um aumento da disponibilidade de nutrientes.

Através da figura 4a, observase que a produção de massa seca (MSA) do substrato $\mathrm{H}+\mathrm{CC}$ fertirrigado foi superior aos demais a partir dos 27DAT. Isso se deve à maior $\mathrm{CRa}$ do substrato $\mathrm{H}+\mathrm{CC}$ fertirrigado (Figura 1) nessa fase do cultivo, que determina maior disponibilidade de nutrientes, numa fase em que o crescimento da cultura é mais intenso. Já os

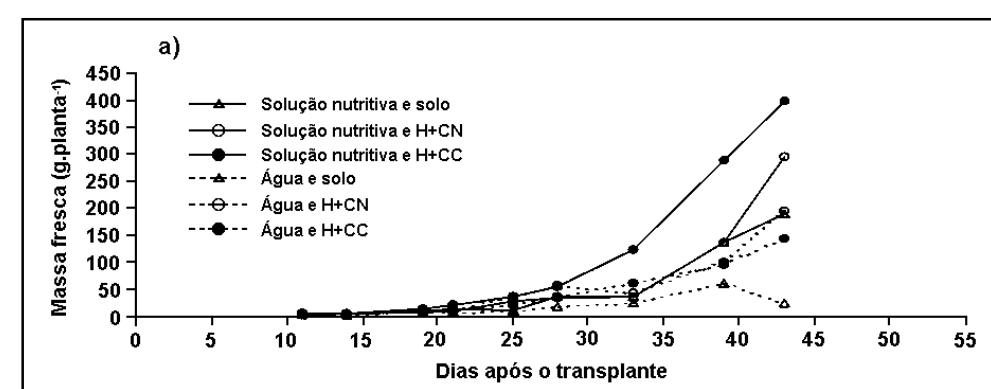

b)

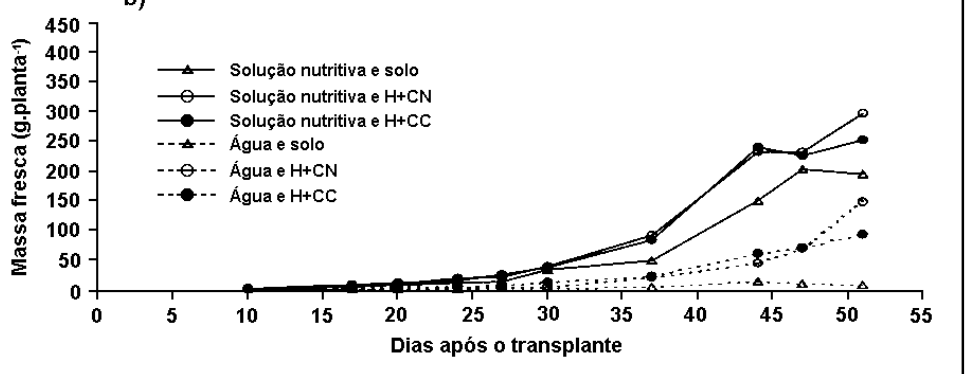

Figura 3 - Evolução da produção de massa fresca da parte aérea (g.planta ${ }^{-1}$ ) da cultivar de alface Brisa cultivada em ambiente protegido por estufa plástica em duas épocas de cultivo, a) outono e b) inverno, em diferentes substratos: húmus de minhoca mais casca de arroz natural $(\mathrm{H}+\mathrm{CN})$, húmus de minhoca mais casca de arroz carbonizada $(\mathrm{H}+\mathrm{CC})$ e solo (testemunha), com e sem solução nutritiva. Santa Maria, RS, 1998.

Ciência Rural, v. 31, n. 2, 2001. 


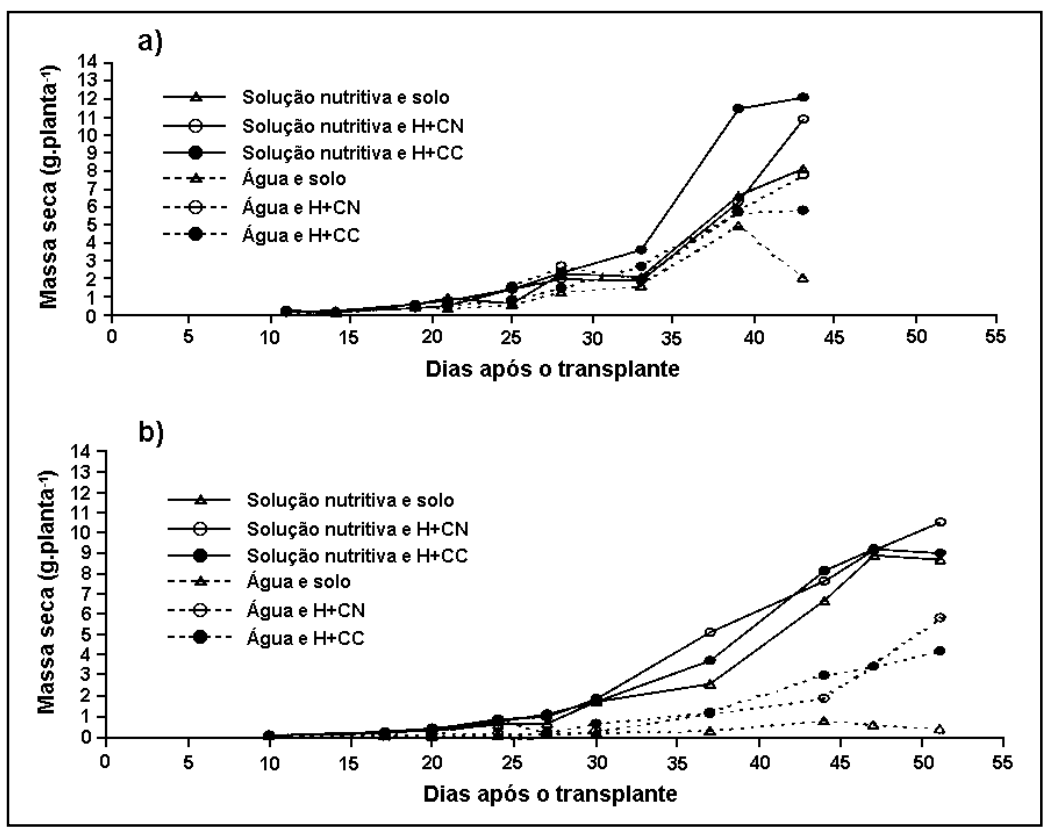

Figura 4 - Evolução da produção de massa seca da parte aérea $\left(\right.$ g.planta $\left.{ }^{-1}\right)$ da cultivar de alface Brisa conduzida em ambiente protegido por estufa plástica em duas épocas de cultivo, a) outono e b) inverno, em diferentes substratos: húmus de minhoca mais casca de arroz natural $(\mathrm{H}+\mathrm{CN})$, húmus de minhoca mais casca de arroz carbonizada $(\mathrm{H}+\mathrm{CC})$ e solo (testemunha) com e sem solução nutritiva. Santa Maria, RS, 1998.

demais substratos apresentam desempenho semelhante (inclusive os irrigados com água) até os 39DAT, a partir do qual, destacamse positivamente o $\mathrm{H}+\mathrm{CN}$ fertirrigado e, negativamente, o solo irrigado com água (Figura 4a). O destaque do $\mathrm{H}+\mathrm{CN}$ fertirrigado a partir dessa data se deve, provavelmente, à continuidade de fornecimento de nutrientes através da solução. A diminuição acentuada na produção de massa seca do substrato solo irrigado com água, a partir de 39DAT, deve-se provavelmente, à senescência e morte de folhas mais velhas das plantas (constatação visual), provavelmente causada pela deficiência de aeração das raízes.

No cultivo de inverno, a superioridade dos substratos fertirrigados em relação aos demais, pode ser observada durante praticamente todo o ciclo. Porém, essa superioridade tornou-se mais evidente a partir dos 30DAT (Figura 4b), período no qual CERMEÑO
(1979) cita que se inicia a fase de crescimento rápido da cultura, quando as exigências nutricionais da planta passam a ser maiores. A perda de nutrientes por lixiviação durante o cultivo de outono, o consumo de nutrientes pelas plantas e a falta de reposição, através da fertirrigação, provavelmente sejam as hipóteses que melhor justifiquem essa superioridade.

Através da figura 5a, pode-se observar, para o cultivo de outono, que a diferenciação no índice de área foliar (IAF) determinado pelos diferentes substratos ocorreu a partir dos 33DAT, período em que iniciou a fase de crescimento rápido da cultura, no qual aumentam as exigências nutricionais da planta. Nesse período, destacou-se o substrato $\mathrm{H}+\mathrm{CC}$ fertirrigado, produzindo um IAF superior aos demais até o final do ciclo, sendo sua superioridade mais acentuada aos 39DAT (Figura 5a). Esse fato pode estar ligado

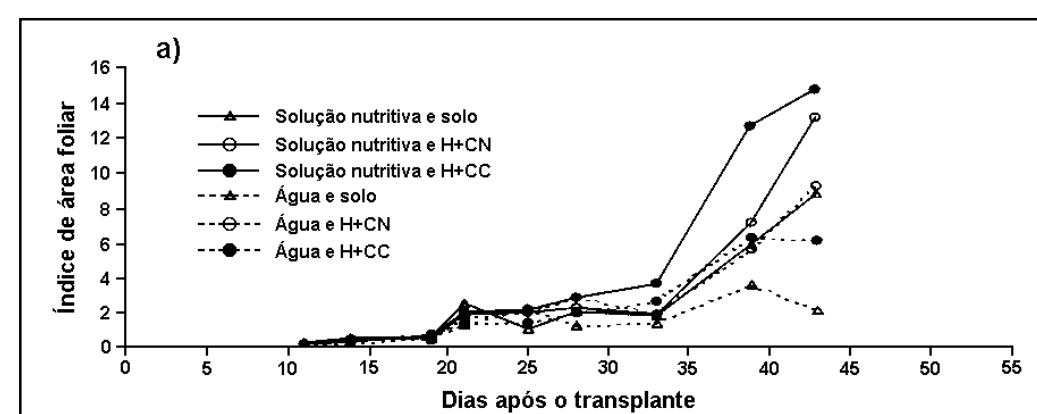

b)

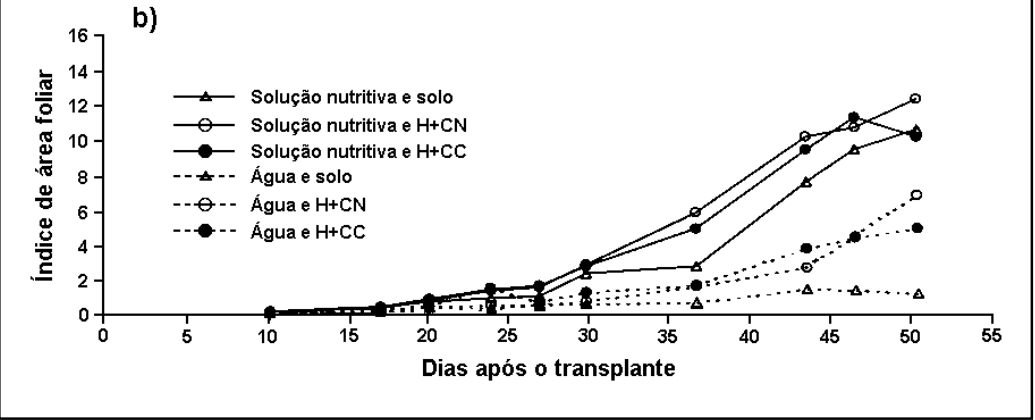

Figura 5 - Evolução do índice de área foliar da cultivar de alface Brisa, conduzida em ambiente protegido por estufa plástica em duas épocas de cultivo, a) outono e b) inverno, em diferentes substratos: húmus de minhoca mais casca de arroz natural $(\mathrm{H}+\mathrm{CN})$, húmus de minhoca mais casca de arroz carbonizada $(\mathrm{H}+\mathrm{CC})$ e solo (testemunha), com e sem solução nutritiva. Santa Maria, RS, 1998.

Ciência Rural, v. 31, n. 2, 2001. 
à sua maior capacidade de retenção nessa fase do cultivo (Figura 1), que determinou melhores condições nutricionais em relação aos demais.

No cultivo de inverno (Figura 5b), não se observa a tendência do substrato $\mathrm{H}+\mathrm{CC}$ fertirrigado em produzir valores de IAF superiores aos demais, na mesma condição de irrigação, conforme o ocorrido no cultivo de outono (Figura 5a). Provavelmente, isso se deva ao fato de que no cultivo de outono, a $\mathrm{CRa}$ do substrato $\mathrm{H}+\mathrm{CN}$ fertirrigado não foi suficiente para atender à demanda nutricional da planta.

\section{CONCLUSÕES}

- A fertirrigação de substratos proporciona maior número de folhas por planta, maior produção de massa fresca e seca e um maior índice de área foliar para a cultivar Brisa de alface, conduzida em estufa plástica.

- A fertirrigação da cultura da alface em estufa plástica é mais indicada para substratos do que para solo.

\section{BIBLIOGRAFIA}

ANDRIOLO, J.L. O cultivo de plantas com fertirrigação Santa Maria : Centro de Ciências Rurais, UFSM, 1996. 47p.
ANDRIOLO, J.L., POERSCHKE, P.R. Cultivo do tomateiro em substratos. Santa Maria : Centro de Ciências Rurais, UFSM, 1997. 12p. (Informe técnico, 2).

BLISKA JÚNIOR., A., HONÓRIO, S.L. Cartilha tecnológica: Plasticultura e estufa. Campinas : n.i., 1996. 85p.

CASTEllane, P.D., ARAÚJO, J.A.C. de. Cultivo sem solo: hidroponia. Jaboticabal : UNESP, 1995. 39p.

CERMEÑO, Z.S. Cultivo de plantas hortícolas em estufa. Lisboa : Litexa, 1979. 368p.

COLJAP INDUSTRIA AGROQUIMICA S.A. Cultivos hidropônicos. Bogotá : Ediciones Culturales Ver [s.d.]. 256p.

LUCCHESI, A.A. Fatores da produção vegetal. In: CASTRO, P.R.C. Ecofisiologia da produção agrícola. Piracicaba : Associação Brasileira para Pesquisa da Potassa e do Fosfato, 1987. p.1-10

SEGOVIA, J.F.O. Influência da proteção ambiental de uma estufa de polietileno transparente sobre o crescimento da alface. Santa Maria, 1991. 76p. Dissertação (Mestrado em Agronomia) - Curso de Pós-graduação em Agronomia, Universidade Federal de Santa Maria, 1991.

STRECK, N.A. Potencial físico da região de Santa Maria para a solarização do solo em estufa plástica. Santa Maria, 1994. 82p. Dissertação (Mestrado em Agronomia) - Curso de Pós-graduação em Agronomia, Universidade Federal de Santa Maria, 1994.

Ciência Rural, v. 31, n. 2, 2001. 